\title{
Distal Bone Lesions Diagnosed by Radiographic Examination in Dairy Cows without Claudication
}

\author{
Antônio Amaral Barbosa, Gabriela Bueno Luz, Aníbal Janczak Torres, Viviane Rabassa, \\ Rafael Ulguim, Francisco Del Pino, Marcio Nunes Correa \& Charles Ferreira Martins
}

\begin{abstract}
Background: During decades, dairy cows have been selected for its productive character, with the main focus on the breeding production, being submitted to constant conditions of metabolic disorders, likewise submitted to permanent or intermittent episodes of systemic and / or mechanical aggression, anatomofunctional of its orthopedic system, appearing locomotion injuries. The present approach brings up the variable aspect of lesions in the extensor process of the third phalanx bone, diagnosed by digital radiography, in 17 Holstein cows, with or without joint involvement, the study was conducted in a commercial farm located in the South of Rio Grande do Sul State, Brazil.

Case: This case report describes the identification and the appearance of lesions on the extensor process of the third phalanx bone in dairy cattle from a commercial herd. 17 Holstein cows with three lactations, with average production in two milking of $30.67 \pm 5.39 \mathrm{~L}$ of milk submitted to semi-extensive system, with daily walk of $2.2 \mathrm{~km}$ between pasture, food and milking parlor. Weekly, the cows were submitted to clinical diagnosis and radiological exploration, on two periods (pre- and postpartum), from 14 days prepartum to 50 days postpartum. All animals despite the zero score of locomotion, demonstrated no abnormalities of posture or walking, however expressed at least one radiographic change in at least one member. Thereafter, radiographic lesions were evaluated for their variety and severity, indeed animals that had only injury extensor process, with fracture and / or joint involvement were detected. In the animals evaluated in this study there was antecedent clinical record of macroscopic lesions to the digit, without lameness. Clinically, the cows manifested macroscopic signs and according to the foot condition frequency was observed: white line extension (23.72\%), scissor claw (22.03\%), horizontal lines (18.64\%), dual sole (13.6\%), wall bleeding (8.47\%), crack in the wall $(6.77 \%)$, corkscrew claw (5.08\%) and a lower frequency of clef white line (1.69\%), and the presence of lameness was not observed. Among the radiographic lesions in thoracic digits, it was found the following array, according with the frequency distribution: proliferative bone reaction in the region of the extensor process in $73.5 \%\left(\mathrm{n}_{\text {nails }}=34\right)$ of forelimbs from the animals, distal interphalangeal osteoarthritis (13.7\%) and extensor process fracture was observed only in $2 \%$ of the digits.

Discussion: In the animals evaluated in this report, there was clinical record of macroscopic lesions antecedent of aggression to the digit, without lameness, even with these bone lesions detected by digital radiographic examination, in other words, chronic lesions in the extensor process, with or without joint involvement, did not promote nociceptive signals in the locomotion of the cows, further emphasizing the importance of digital imaging in the detection of relevant subtle lesions that may subsequently lead to serious failings by the involvement of the distal interphalangeal joint. The technology of digital radiology provides a higher accuracy of diagnosis of lesions on the locomotor system, nevertheless, in dairy cattle, its use is still limited when compared to horses. Up to now, there are few studies that report the occurrence of lesions in the extensor process of the third phalanx in cattle. Extensor process lesions may be more common in dairy herds, given the absence of complementary diagnostics.
\end{abstract}

Keywords: complementary diagnostic, hoof, proliferative bone reaction. 


\section{INTRODUCTION}

With the advance of genetic progress, dairy cows are increasingly challenged, being submitted to constant conditions of metabolic disorders, likewise submitted to permanent or intermittent episodes of systemic and / or mechanical aggression, anatomofunctional of its orthopedic system, appearing locomotion injuries, which until then fewer studies have been reported in bovines, such as orthopedic diseases located in supporting tissues of the digits [5].

In horses, the distal phalanx (F3) can be affected by laminitis, osteitis, fractures, hoof abscesses and remodeling in flexion deformities [9]. Fractures of the distal phalanx are well known orthopedic conditions, which usually occur as a result of severe trauma to the plant digit, requiring further examination by imaging for definitive diagnosis [2].

Historically, these lesions on F3 have been associated with constant periosteal stimulus on the extensor region of the third phalanx, clinically showing nociceptive signals to palpation, and added swelling in the face proximal dorsal of the coronary band with possible deformations of the hoof horn on the same aspect [9]. There is variation both in extent and in degree of severity of complications in this region, especially when surrounding anatomical structures are involved [6], nevertheless this task have been tentatively investigated in dairy cattle, even less the routine use of complementary diagnostics, such as X-ray evaluations on the herd management [7], which could display dynamic instability of motion.

Therefore, this study reports the frequency and variation of lesions in the extensor process of the third phalanx bone, with or without joint involvement in dairy cows.

\section{CASE}

This case report describes the identification and the appearance of lesions on the extensor process of the third phalanx bone in dairy cattle from a commercial herd located in the South of Brazil ( $32^{\circ} 16$ ' $\mathrm{S}, 52^{\circ} 32^{\prime}$ E), with sandy soil, average annual rainfall of $1207 \mathrm{~mm}$.

Seventeen Holstein cows with three lactations, with average production in two milking of $30.67 \pm$ $5.39 \mathrm{~L}$ of milk and average weight of $656.89 \pm 92.6 \mathrm{~kg}$ were evaluated. The animals were submitted to semi-extensive system, with daily walk of $2.2 \mathrm{~km}$ between pasture, food and milking parlor.
Weekly, the cows were submitted to clinical diagnosis and radiological exploration, on two periods (pre- and postpartum), from 14 days prepartum to 50 days postpartum, being held under the same management conditions. Clinically, the cows manifested macroscopic signs of bleeding soles, presence of cracks and / or bleeding white line, ulcers or sole abscesses, yellow soft soles, crack in the wall, scissor claw or corkscrew claw and stress lines in the walls, the frequency of these observations are shown in Table 1, but the presence of lameness was not observed [3].

The complementary radiological exams were performed with digital equipment $(68 \mathrm{Kv} ; 0,05 \mathrm{~s}$. brand: Cuattro ${ }^{\circledR}$ model: Slate 2$)^{1}$, in which the forelimbs were bilaterally radiographed in lateromedial projection, in order to determine possible radiographic change present in members.

All animals despite the zero score of locomotion, demonstrated no abnormalities of posture or walking, however expressed at least one radiographic change in at least one member.

Thereafter, radiographic lesions were evaluated for their variety and severity, indeed animals that had only injury extensor process, with fracture and / or joint involvement were detected.

Among the radiographic lesions observed, it can be seen that the proliferative bone reaction in the region of the extensor process (Figure 1) was diagnosed in $73.5 \%\left(\mathrm{n}_{\text {nails }}=34\right)$ of the forelimbs of the animals.

In addition, this same injury, extending to the distal interphalangeal joint (Figure 2) was observed in $13.7 \%$ of the members. On a smaller scale, fractures (Figure 3 ) were identified on $2 \%$ of animals, while $10.8 \%$ had no abnormalities (Figure 4) in a member, however it is important to note that bilateral healthiness of both forelimbs was not observed.

Table 1. Foot condition frequency observed in Holstein cows.

\begin{tabular}{ccc}
\hline Foot condition & Cases & Percentage \\
\hline White line extension & 14 & $23.72 \%$ \\
Scissor claw & 13 & $22.03 \%$ \\
Horizontal lines & 11 & $18.64 \%$ \\
Dual sole & 8 & $13.6 \%$ \\
Wall bleeding & 5 & $8.47 \%$ \\
Crack in the wall & 4 & $6.77 \%$ \\
Corkscrew claw & 3 & $5.08 \%$ \\
Cleft White line & 1 & $1.69 \%$ \\
Total & 59 & $100 \%$ \\
\hline
\end{tabular}




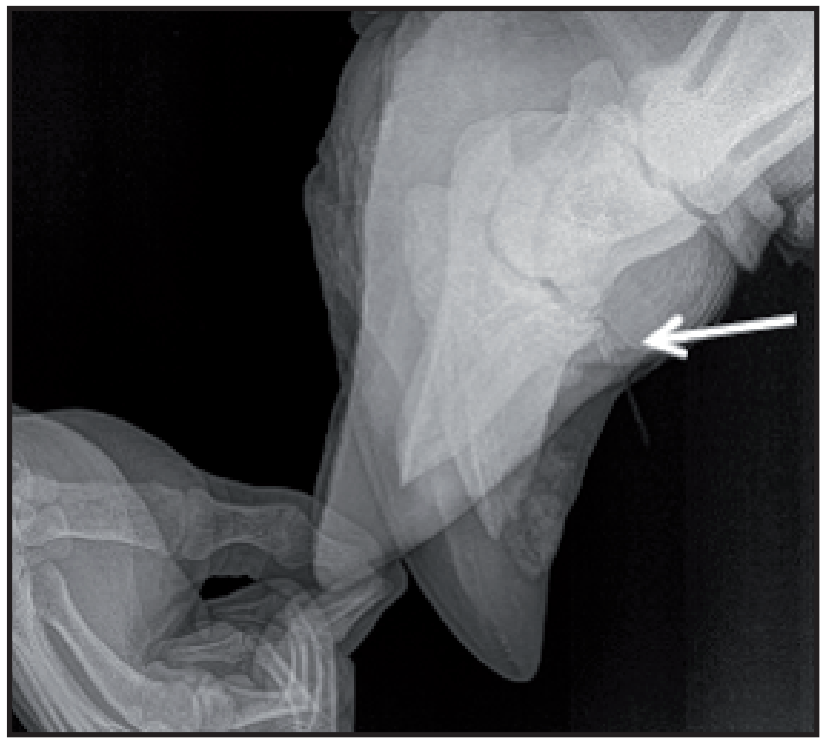

Figure 1. Radiographic lesions of proliferative bone reaction in the region of the extensor process observed in the members of cows evaluated.

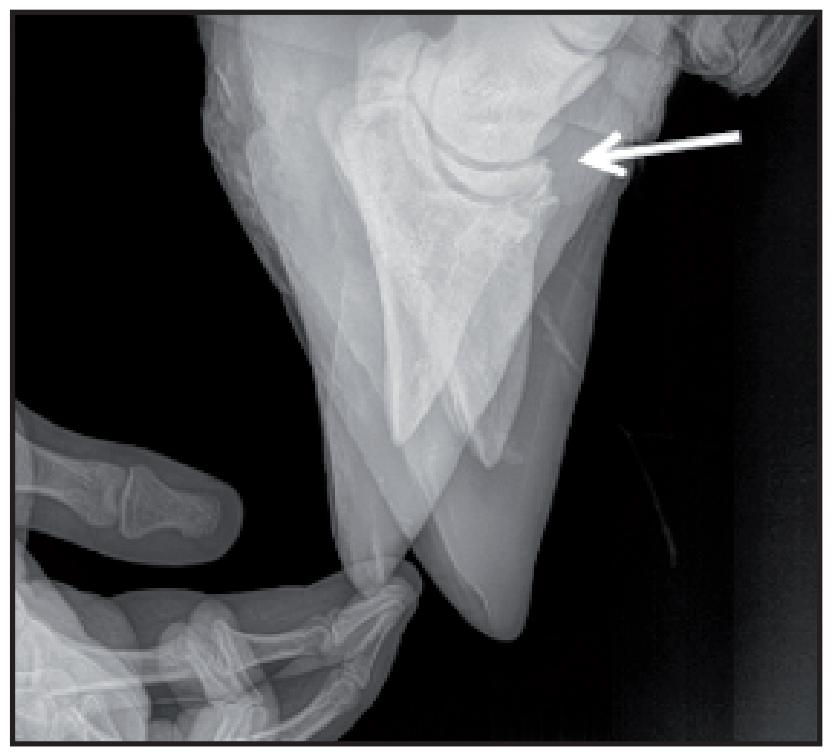

Figure 2. Radiographic lesions of proliferative bone reaction in the region of the extensor process extending to the distal interphalangeal joint observed in the members of cows evaluated.

\section{DISCUSSION}

In the animals evaluated in this report, there was clinical record of macroscopic lesions antecedent of aggression to the digit, without lameness, even with these bone lesions detected by digital radiographic examination, in other words, chronic lesions in the extensor process, with or without joint involvement, did not promote nociceptive signals in the locomotion of the cows, further emphasizing the importance of digital imaging in the detection of relevant subtle lesions that may subsequently lead to serious failings by the involvement of the distal interphalangeal joint.

It is likely that more severe osteoarthritis damage, bilaterally, are necessary for the manifestation of

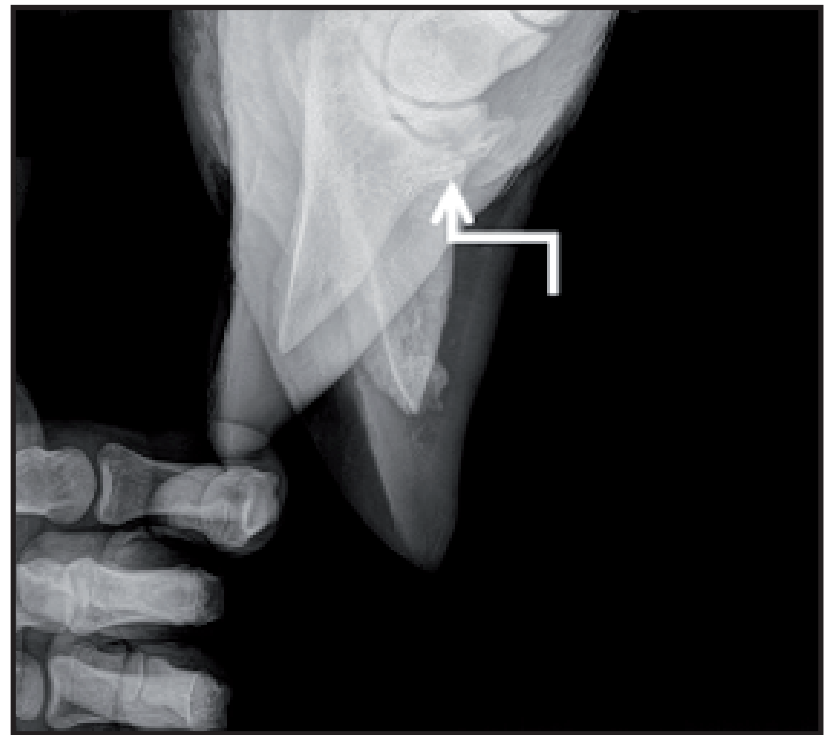

Figure 3. Radiographic of fractures observed in the members of cows evaluated.

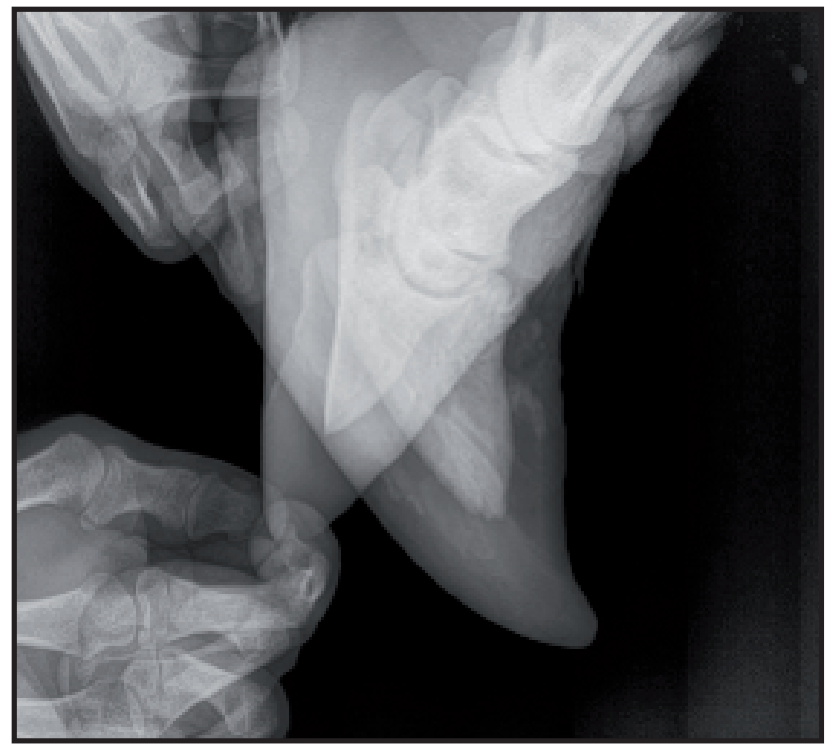

Figure 4. Radiographic of the members of cows with no abnormalities.

lameness. However, may a deviation from the center of support for the contralateral digit of the forelimb, that shows the lesion reduces the biomechanical stress and painful to the affected region, thus, the use of complementary exams such as radiology and ultrasonography are requirements, in some cases, for diagnosing podal diseases in cattle due to the indication of extent lesions, the pathology and the most likely prognosis [1], especially when the lesions are unilateral to the same digit.

In this study, can be considered that the lesions to the extensor process may have been caused by repeated biomechanical stress caused by the irregularity of the ground surface, associated with the distance that the cows walk at the farm. 
Additionally, to these factors, the excessive humidity condition of the farm soil promotes the formation of undulations that have probably contributed to the locomotor imbalances of the animals, leading to overextension of the joint and the dorsal digital extensor tendon to the insertion to the pyramidal process of the third phalanx, which had been reported in horses [4].

Some of these etiological factors were already described [2], emphasizing that irregular surfaces, long walks, estrous behavior, weight, excessive hoof growth and advanced age are predisposing factors for foot lesions.

The shaft misalignment prune phalangeal and bulbar pain may also contribute to increased biomechanical stress with constant assaults on proximal site of insertion of the extensor process of the distal interphalangeal joint portion.

A slight bone reaction on the dorsal surface of the distal phalanx may suggest an early sign of laminitis in horses [9], however, in bovines have not yet exist surveys to consider this relationship. In the animals evaluated was not observed the existence of radiographic signs of laminitis, also no change in the positioning of the $\mathrm{F} 3$ front of the hoof capsule in cattle was analyzed, disconcerting the interrelationship.

According to reported by others authors [8], in horses, fractures or injuries to the extensor process derived from chronic events, usually traumatic, being diagnosed as findings on routine, that do not present evident lameness in the specie. Furthermore, this data agrees with the case study reported, whereas lameness was not observed, despite the presence of evident lesions in radiographic extensor process. But when diagnosis involves joint lesions these authors described as major etiological factors the advanced age, fractures on F3 and subchondral lesions. However, it disagrees with the present study, in which the cows evaluated were in an intermediate age group ( $\mu=5$ years) and only $2 \%$ had lesions of fracture, so they probably were not given these causes as precursors of aggression to this region.

If these animals do not show irreversible damage to the mammary and / or reproductive syste- $\mathrm{ms}$, their permanence in the production cycle can be compromised given the possibility of expression of relevant nociceptive signals caused by degenerative osteoarthritis disorders interphalangeal with negative dynamic reflections on digital biomechanics.

Currently, most diagnoses of foot diseases in cattle occurs only at specific and general clinical examination of the musculoskeletal system, however, Parizi and Shakeri [7] demonstrated that the use of radiography was essential for differential bone and joint diseases in animals with lameness. Radiographic examination is an excellent diagnostic imaging method for lesions involving the orthopedic system in horses. The technology of digital radiology provides a higher accuracy of diagnosis of lesions on the locomotor system [8], nevertheless, in dairy cattle, its use is still limited when compared to horses [6].

Up to now, there are few studies that report the occurrence of lesions in the extensor process of the third phalanx in cattle [10]. Extensor process lesions may be more common in dairy herds, given the absence of complementary diagnostics. Therefore, further studies are needed to confirm the importance and its relation with predisposing factors in rural establishments.

The severity of radiographic findings in the extensor process of the F3 was not related to the score of locomotion, suggesting insidious character of the lesions in the population studied. The proliferative bone reaction in the region of the extensor process was the most evident lesion in cattle. Radiographic examination showed the extent of bone changes in cattle with subclinical laminitis, providing important information for diagnosis and prognosis of associated lesions.

\section{MANUFACTURER}

${ }^{1}$ Cuattro Veterinary USA. Loveland, CO, EUA.

Acknowledgments. To the Núcleo de Pesquisa, Ensino e Extensão em Pecuária (NUPEEC) and Granjas 4 Irmãos S.A. for providing the database.

Declaration of interest. The authors report no conflicts of interest. The authors are responsible for the content and writing of the paper. 


\section{REFERENCES}

1 Bargai U., Pharr J.W. \& Morgan J.P. 1989. Radiological diagnosis. In: Bovine radiology. Ames: Iowa State University Press, 198p.

2 Blowey R.W. 2008. Claudicações. In: Medicina Bovina: doenças e criação de bovinos. 2.ed. São Paulo: Editora Roca, pp.362-384.

3 Ferreira P.M., Leite R.C., Carvalho A.U., Facury Filho E.J., Souza R.C. \& Ferreira M.G. 2004. Custo e resultados do tratamento das sequelas de laminite bovina: relato de 112 casos em vacas em lactação no sistema free stall. Arquivo Brasileiro de Medicina Veterinária e Zootecnia. 56(5): 589-594.

4 Kaneps A.J., O'brien T.R., Redden R.F., Stover S.M. \& Pool R.R. 1993. Characterisation of osseous bodies of the distal phalanx of foals. Equine Veterinary Journal. 25(4): 285-292.

5 Lima I.R., Fonseca A.M., Silva L.H., Costa A.P.A., Silva L.A.F. \& Borges N.C. 2009. Estudo radiográfico das extremidades distais dos membros locomotores de bovinos com claudicação. Ciência Animal Brasileira. (1): 423-429.

6 Nouri M., Vajhi A., Marjanmehr S.H., Nowrouzian I. \& Faskhoudi D. 2013. Post-mortem qualitative radiographic study of the foot with special reference to the digital lesions in culling lame cows. Animal and Veterinary Science. 1(4): 27-31.

7 Parizi A.M. \& Shakeri M.A. 2007. Abattoir study of radiographic changes of bones and joints of digital region in cattle with abnormal claws. Veterinarski ARHIV. 77(2): 187-194.

8 Ross M.W. \& Dyson S.J. 2003. Diagnosis and management of lameness in the horse. 2nd edn. St. Louis: Saunders, $1424 \mathrm{p}$.

9 Stashak T.S. 2004. Claudicación, el pie. In: ADAMS: Claudicación en el caballo. 5.ed. Buenos Aires: Editorial InterMédica, pp. 685-706.

10 Taguchi K., Nakamura S. \& Hyakutake K. 2010. Fracture of the extensor process of the distal phalanx in a bull and a cow. Veterinary Record. 167(23): 904-906. 